Submission ID: 43876

\title{
Criteria for Evaluating the Effectiveness of Exploration Work in the West
} Siberia

L. Saratinian* (LUKOIL-Engineering Limited KogalymNIPIneft Branch in Tyumen), S. Lats (LUKOILEngineering Limited KogalymNIPIneft Branch in Tyumen), A. Kachkin (LUKOIL-West Siberia)

\section{SUMMARY}

Estimating efficiency of exploration works at LUKOIL-West Siberia it should be noted that it is difficult process of interaction of the mining-and-geological, technical, economic and social aspects of production. Such versatility of components of efficiency of GRR predetermines an integrated approach to her accounting and interpretation of results. The operating criteria for evaluation of efficiency of exploration works don't reflect the actual annual production rate of exploration works in the West Siberia. Change of strategy of conducting search and investigation of fields strengthen influence of physical indicators while economic indicators of efficiency of exploration works show the return picture. 
О критериях оценки эффективности геологоразведочных работ в ООО «ЛУКОЙЛЗападная Сибирь»

Л.В. Саратинян*, С.А. Лац (Филиал ООО «ЛУКОЙЛ-Инжиниринг» «КогалымНИПИнефть» в г. Тюмени), А.А. Качкин (ООО «ЛУКОЙЛ-Западная Сибирь»)

\section{Введение}

Оценивая эффективность геологоразведочных работ в ООО «ЛУКОЙЛ-Западная Сибирь» следует отметить, что это сложный процесс взаимодействия горно-геологических, технических, экономических и социальных сторон производства. Такая многогранность составляющих эффективности геологоразведочных работ предопределяет комплексный подход к её учету и интерпретации результатов.

Традиционно к базовым классическим критериям оценки эффективности геологоразведочных работ относятся объемы прироста запасов углеводородов и объемы поисково-разведочного бурения (рисунок 1).

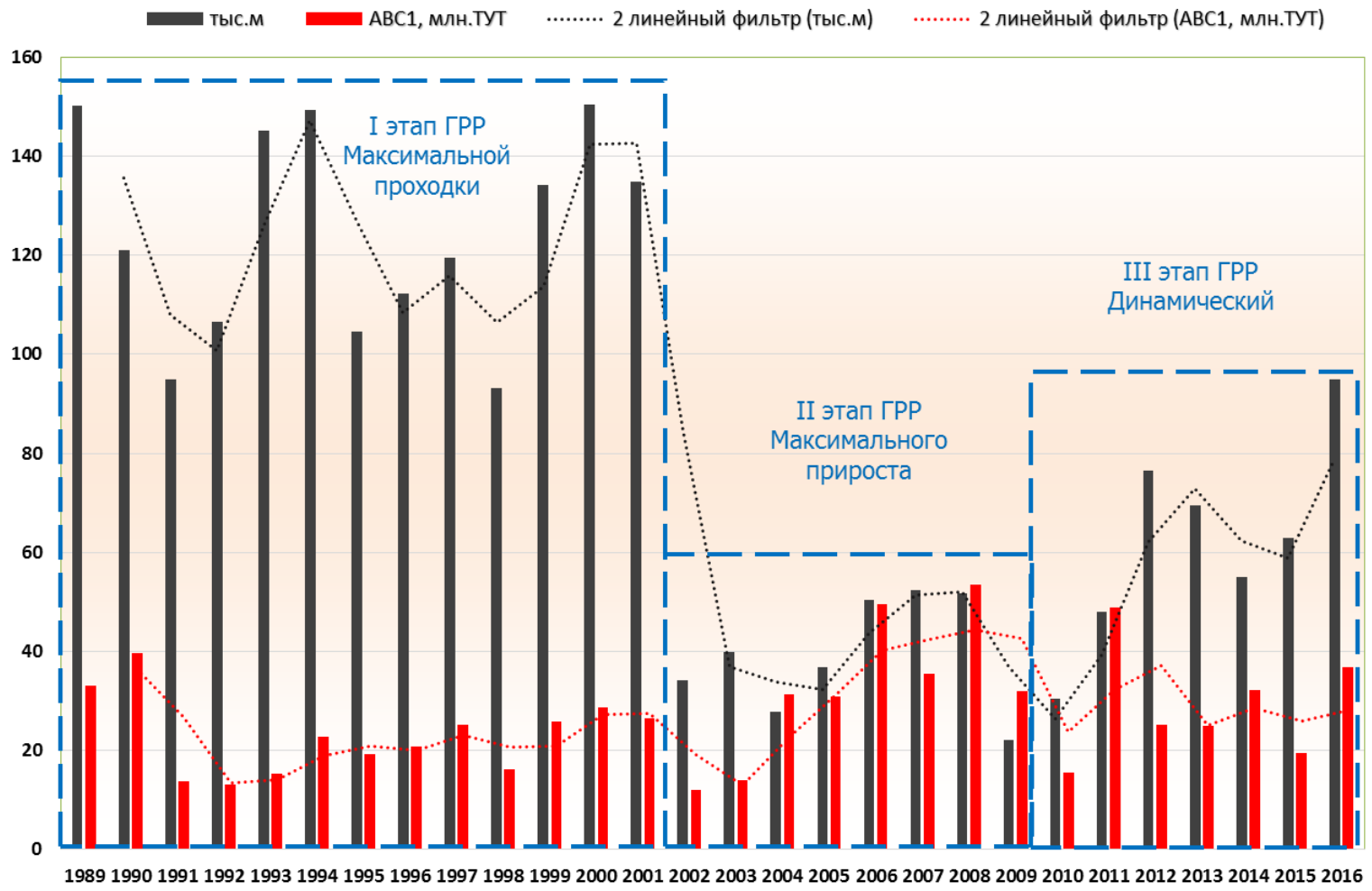

Рисунок 1 Этапы геологоразведочных работ, выделенные по соотнотению объемов прироста запасов углеводородов и проходки поисково-разведочного бурения ООО «ЛУКОЙЛ-Западная Сибирь»

А также различные вариации их взаимного соотношения, такие как (рисунок 2):

• количество углеводородов, приходящееся на 1 м проходки, «ТУТ/м»;

- стоимость подготовки запасов углеводородов, «/т»;

• удельный прирост запасов углеводородов, «ТУТ/скв.».

С 2009 года по настоящее объемы выполняемых работ в денежном и физическом выражении перестали быть объективными показателями состояния и динамики развития геологоразведочных работ в ООО «ЛУКОЙЛ-Западная Сибирь», что служит началом поиска новых критериев оценки годовой производительности труда геологоразведки (рисунок 2). 


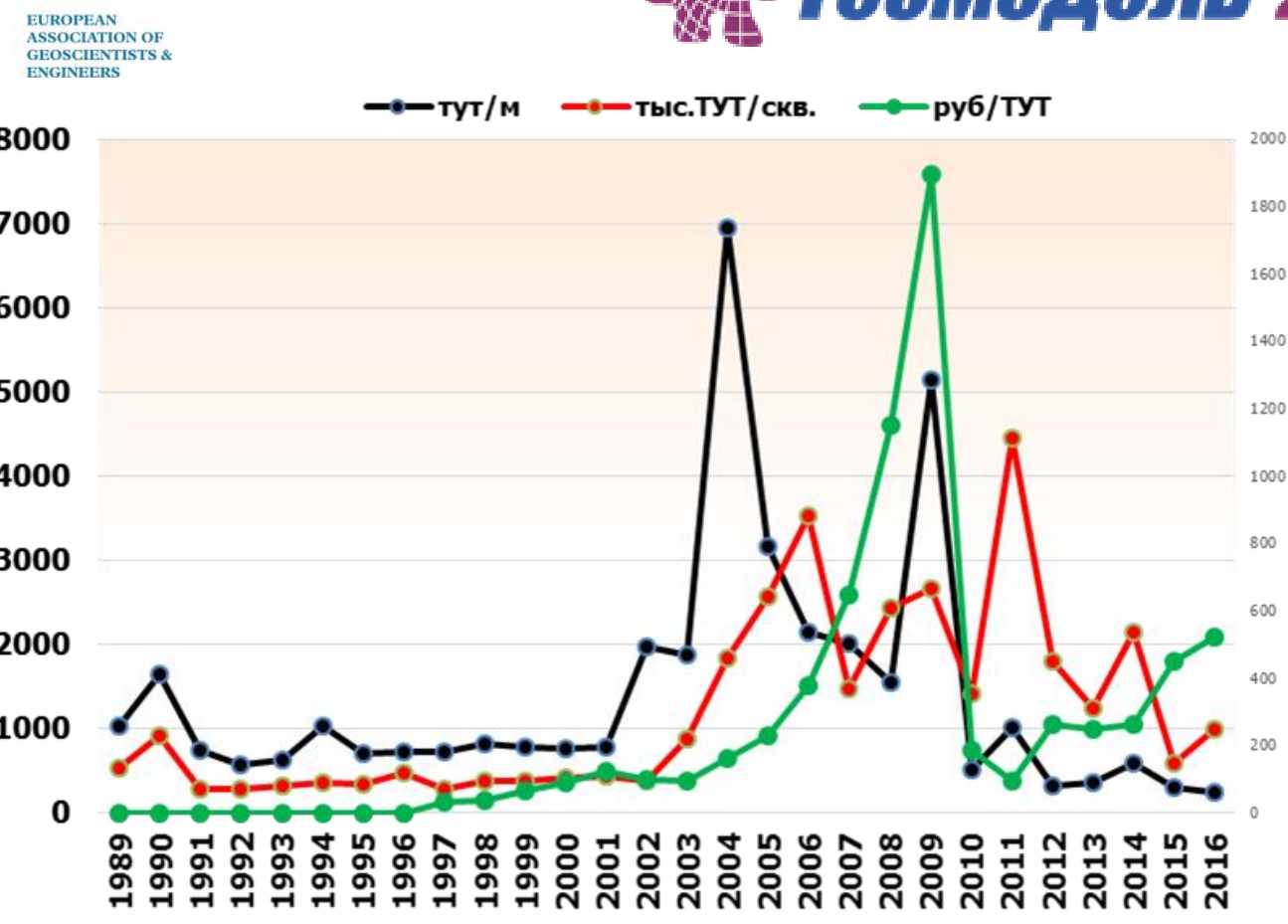

Рисунок 2 Динамика показателей эффективности геологоразведочных работ в ООО «ЛУКОЙЛ-Западная Сибирь»

Отмечается ряд неопределенностей. По результатам анализа традиционных показателей эффективности геологоразведка в ООО «ЛУКОЙЛ-Западная Сибирь» переживает глубокий кризис (рисунок 2) - при росте объемов бурения и инвестиций кривая годового прироста запасов показывает дефицит потенциала для восполнения добычи. При этом по результатам анализа физических объемов геологоразведочных работ, как альтернативных показателей эффективности, очевидна положительная динамика, интерпретация которой показывает достаточно хорошую картину организации геологоразведки по воспроизводству минеральносырьевой базы в ООО «ЛУКОЙЛ-Западная Сибирь» (рисунок 3).

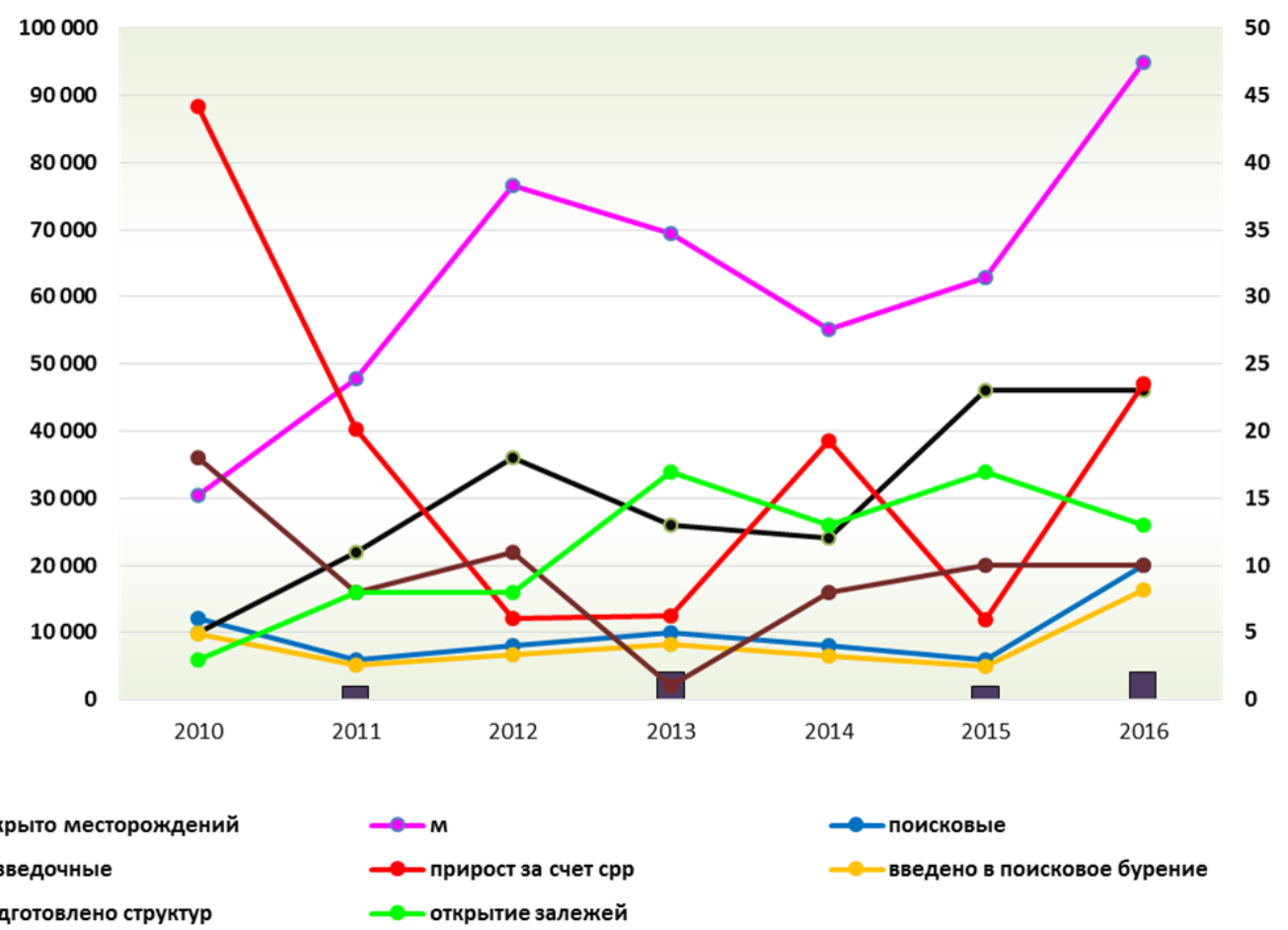

Рисунок 3 Динамика физических показателей годовой эффективности геологоразведочных работ в ООО «ЛУКОЙЛ-Западная Сибирь». 


\section{EAGE}

Очевидно, что традиционный показатель эффективности геологоразведочных работ - прирост на метр походки «ТУТ/м» (рисунок 2) уже не является определяющим, а разведочное бурение хотя и остается основным способом достижения конечного результата, но находится под влиянием других видов и методов работ, таких как опережающее эксплуатационное, углубленное бурение, доиспытание, что нарушает планирование прироста запасов в структуре геологоразведочных работ и объективную оценку годовой производительности геологоравзедочных работ.

Объективно количественный объем прироста запасов стал действительно меньше, чем, например, в 2008, 2013 годах (рисунок 1), но качество прироста, выражающееся в вовлекаемости прироста в разработку несомненно выше (рисунок 4).
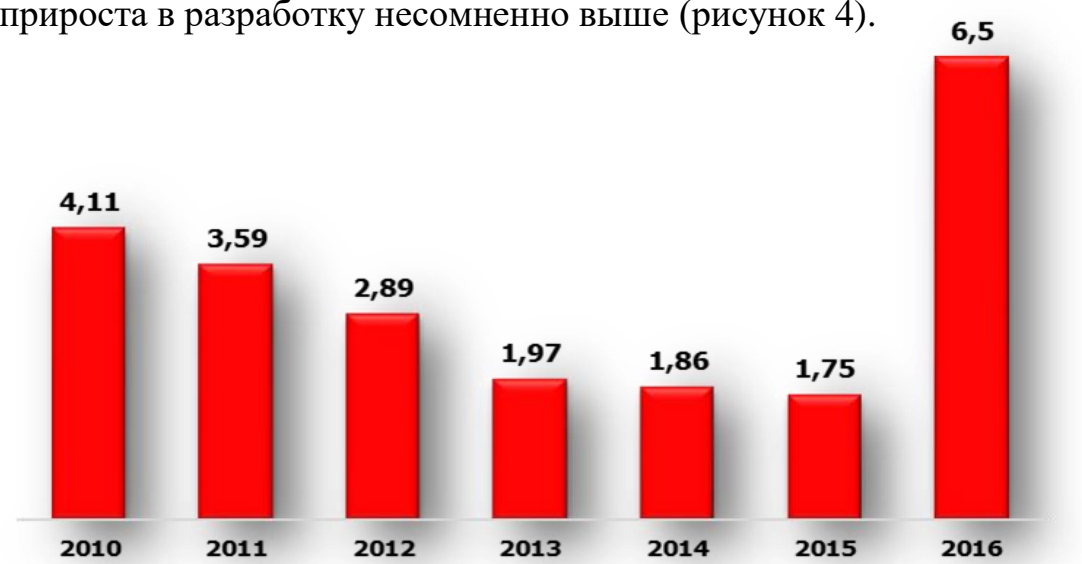

Рисунок 4 Динамика вовлекаемости прироста углеводородов в разработку как показателя годовой эффективности геологоразведочных работ в ОО «ЛУКОЙЛ-Западная Сибирь»

Аналогичную неопределенность показывает и устойчивый рост открытий месторождений и залежей при отрицательной динамике показателя «ТУТ/м» (рисунок 5).

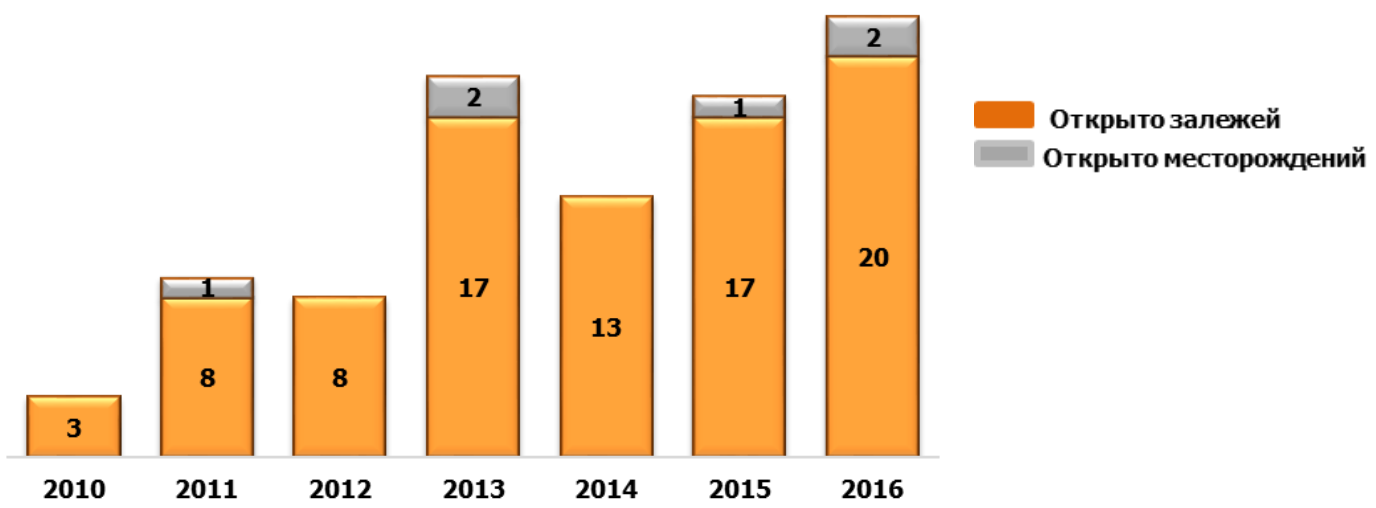

Рисунок 5 Динамика открытия месторождений и залежей в ООО «ЛУКОЙЛ-Западная Сибирь»

Отмечается тесная корреляционная связь прироста запасов углеводородов с объемами сейсморазведки $3 \mathrm{D}$. Подобная корреляционная зависимость прироста запасов не устанавливалась ни с одним из ключевых физических объемов или расчетных показателей геологоразведочных работ (рисунок 6). Если взятое направление в сейсморазведке по увеличению ресурсного потенциала развивать далее, то о будущем ООО «ЛУКОЙЛ-Западная Сибирь» в части обеспеченности добычи можно не беспокоиться. 


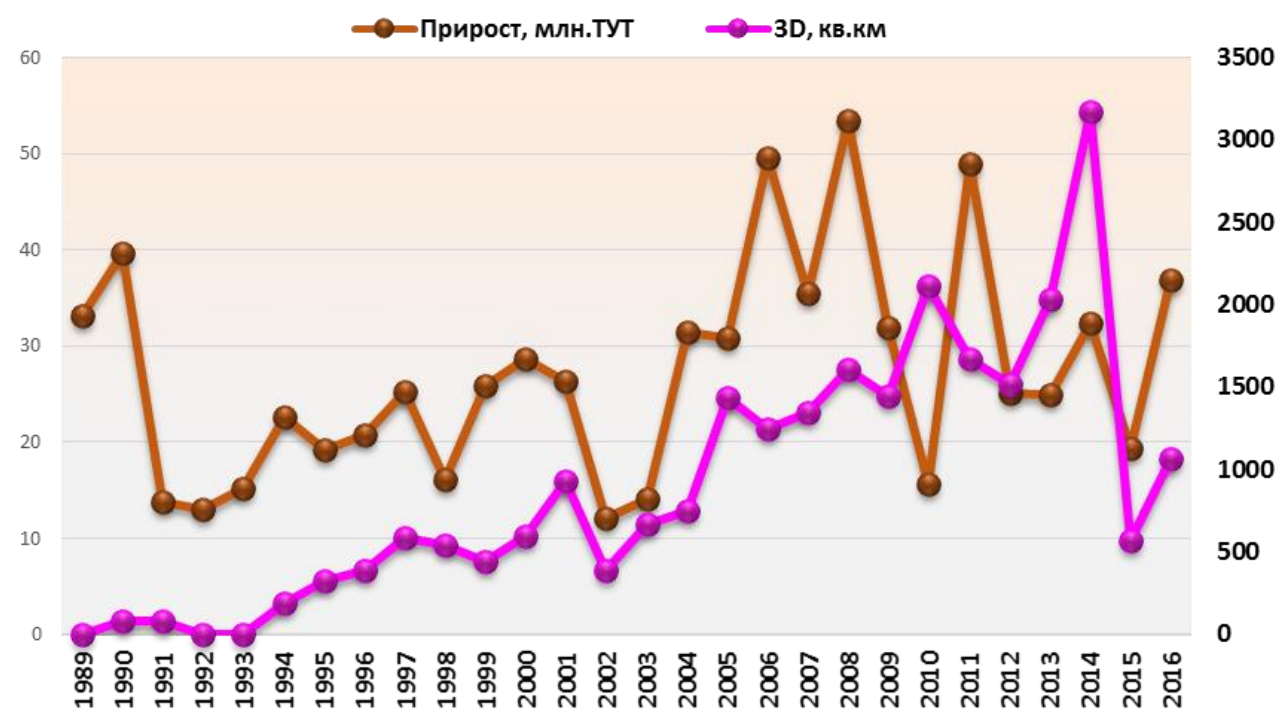

Рисунок 6 Соотношение динамики прироста запасов углеводородов с объемами сейсморазведочных работ

Объемы и эффективность геологоразведочных работ в современных условиях экономики, лицензирования и недропользования являются самой проблемной стороной геологии. Понятно, что возврата к многолетней «советской» организации поисковых и разведочных работ не будет, но и новых критериев оценки эффективности геологоразведочных работ нет.

\section{Выводы}

В истории геологоразведочных работ ООО «ЛУКОЙЛ-Западная Сибирь» планомерно сменились 3 этапа, выделенные по сочетанию экономических, социальных и геологогеофизических факторов.

Прирост запасов УВ и объем бурения - базовые критерии оценки эффективности геологоразведочных работ и материал для расчета удельных коэффициентов. Однако, текущий 10-летний этап геологоразведочных работ показывает, как некорректно интерпретируются данные показатели между собой.

Согласно традиционным взглядам на годовую оценку эффективности геологоразведочных работ - чтобы достичь уровня прироста, сопоставимого с объемами проходки нужно бурить в 10 раз больше разведочных скважин. С учетом ежегодной инфляции и удорожания стоимости подготовительных и буровых работ, инвестиции в геологоразведочные работы станут исчисляться десятками миллиардов, что, во-первых, в современных условиях невозможно достичь, а во-вторых этого не нужно достигать, потенциала для производства и успешного выполнения работы по воспроизводству запасов достаточно.

Для корректной оценки годовой производительности геологоразведочных работ, кроме традиционных удельных коэффициентов, рекомендуется использовать ключевые показатели физических объемов: прирост ресурсов $\mathrm{C}_{3}$ (До) за счет сейсморазведки; количество подготовленных и введенных в бурение структур; открытие залежей, месторождений; количество разведочных и поисковых скважин и т.д.

\section{Библиография}

1. Крылов Н.А. Геолого-экономический анализ освоения ресурсов нефти / Н.А. Крылов, Ю.Н. Батурин. - М: Недра, 1990. - 152 с.

2. Методические рекомендации по анализу результатов и оценке эффективности геологоразведочных работ на нефть и газ / Под редакцией Лейбсона. - М.Г.Л: ВНИГРИ, 1977. 3. Джонсон Д. Анализ экономики геологоразведки, рисков и соглашений в международной нефтегазовой отрасли / Д. Джонсон. - М.: Олимп-Бизнес, 2005. 


\section{EAGE}

\section{References}

1. Krylov N.A. Geologo-ekonomicheskiy analiz osvoyeniya resursov nefti / N.A. Krylov, YU.N. Baturin. - M: Nedra, 1990. - $152 \mathrm{~s}$.

2. Metodicheskiye rekomendatsii po analizu rezul'tatov i otsenke effektivnosti geologorazvedochnykh rabot na neft' i gaz / Pod redaktsiyey Leybsona. - M.G.L: VNIGRI, 1977.

3. Johnson D. Analiz ekonomiki geologorazvedki, riskov i soglasheniy $\mathrm{v}$ mezhdunarodnoy neftegazovoy otrasli / D. Johnson. - M.: Olimp-Biznes, 2005. 